\title{
Stress and Growth in Children and Adolescents
}

\author{
Maria Mousikou ${ }^{a} \quad$ Andreas Kyriakou $^{a} \quad N_{i c o s}$ Skordis ${ }^{b, c}$

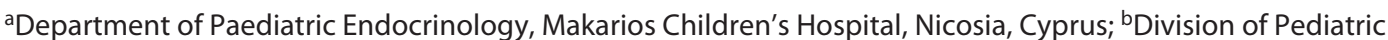 \\ Endocrinology, Paedi Center for Specialized Pediatrics, Nicosia, Cyprus; ' $S$ School of Medicine, University of Nicosia, \\ Nicosia, Cyprus
}

\section{Keywords}

Normal growth · Chronic stress · Neuroendocrinology of stress response $\cdot$ Early-life adversities

\begin{abstract}
The infantile, childhood, and adolescent periods of growth and development also represent times of increased vulnerability to stressors. Growth velocity in each period is dependent on the interplay of genetic, environmental, dietary, socioeconomic, developmental, behavioral, nutritional, metabolic, biochemical, and hormonal factors. A stressor may impact growth directly through modulation of the growth hormone axis or indirectly through other factors. The adaptive response to stressors culminates in behavioral, physiological, and biochemical responses which together support survival and conservation of energy. The immediate response involves activation of the sympathetic nervous system and the hypothalamic-pituitary-adrenal axis. The time-limited stress response is at once antigrowth, antireproductive, and catabolic with no lasting adverse consequences. However, chronic activation of the stress system and hypercortisolism have consequential negative impacts on growth, thyroid function, reproduction-puberty, and metabolism. High cortisol suppresses growth hormone-insulin-like growth factor 1, hypothalamic-pituitary-gonadal, and thyroid axes and has been reported to be responsible for an increase in visceral adiposity, a decrease in lean mass, suppression of osteoblastic
\end{abstract}

activity with risk of osteoporosis, and induction of insulin resistance. Early-life adversities, emotional or physical, have been associated with long-term negative physical and mental health outcomes. Existing models of chronic stress corroborate that early-life adversities can affect growth and have consequences in other aspects of well-being throughout the lifespan. Targeted interventions to reduce stress during infancy, childhood, and adolescence can have far-reaching benefits to long-term health as well as attaining adequate growth. In this review, we describe the neuroendocrinology of the stress response, the factors influencing growth, and the impact of chronic stress on growth during critical periods of infancy, childhood, and puberty with particular reference to growth, thyroid, and gonadal axis.

(c) 2021 S. Karger AG, Basel

\section{Introduction}

Growth is necessary for the conservation of human life. Auxology comes from Greek ( $a v ้ \xi \omega, a u x \bar{o}$, or $a u ̉ \xi \alpha \dot{ } v \omega$,

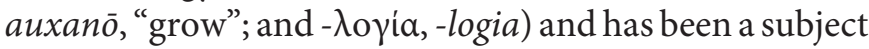
of study for many ancient civilizations [1].

There are 4 distinct phases of human growth: antenatal/ fetal, infancy, childhood, and puberty, which ultimately determine adult height [2]. The prenatal/fetal period is determined by many different factors including gestational age and maternal factors such as body size, uterine growth karger@karger.com

www.karger.com/hrp (c) 2021 S. Karger AG, Basel 
potential, nutrition, diabetes, blood pressure, and smoking [3]. Every child has a predetermined genetic growth potential, which may be modulated by factors both in the prenatal period and in postnatal life [4]. Postnatal growth maybe affected by various factorsincluding prenatal growth, genetics, nutrition, socioeconomics, psychosocial, physical activity, urbanization, and disease [5]. Growth during infancy depends largely on nutrition, but after the first 2 years of life, the hormonal regulators become more important. During puberty, sex steroids are responsible for the expected pubertal growth spurt. Optimal growth can only be achieved when all these factors operate in harmony [5].

Stress is defined as a state of threatened or perceived threatened homeostasis. The human body and mind react to stress by activating both adaptive central nervous system (CNS) and peripheral nervous system responses. This is the "fight or flight" response $[6,7]$. The adaptive response to stressors is protective in the survival of human life. In circumstances where the stressors have greater magnitude or persist longer, the stress response may be maladaptive - either inadequate or excessive. A maladaptive stress response may contribute to poor health outcomes $[6,7]$.

The adaptive response to stress is determined by genetic, environmental, and developmental factors. Prenatal life, infancy, childhood, and adolescence are critical periods characterized by increased vulnerability to stressors. If the magnitude or duration of a stressor is too large or long to permit restoration of homeostasis by adaptive processes, then growth, metabolism, reproduction, and inflammatory/immune response will be adversely affected [7]. The review is divided into the following sections: (i) the stress system and neuroendocrinology of stress response; (ii) factors of optimal growth during childhood and adolescence; (iii) growth-related hormonal adaptive response of stress; (iv) adversities and the consequences; (v) models of chronic stress affecting growth, with particular reference to growth, thyroid, and gonadal axis.

\section{The Stress System and Neuroendocrinology of Stress Response}

A stressor can be physical or psychological/emotional or a combination of both. Physical stressors include disturbances of the internal environment (anoxia and hypoglycemia), external extremes (heat and cold), and multifaceted stressors (exercise and injury). Psychological/emotional stressors can include fear, anxiety, or frustration. Any stressor can activate the hypothalamic-pituitary-adrenal
(HPA) axis [8]. The quality (physical or psychological), strength, and duration (acute or chronic) of any stressor, as well as constitution and state of the organism, influence the adaptive response to stress [9].

The stress system consists of neuroanatomical and functional networks that produce behavioral, physiological, and biochemical changes to ensure maintenance of homeostasis. Any stressor is met with an adaptive central and peripheral response with aims of achieving restoration of homeostasis $[6,8]$.

Behavioral adaptation comprises increased arousal and alertness, increased cognition, vigilance and focused attention, euphoria or dysphoria, heightened analgesia, increased temperature, and suppression not only of feeding but also of reproductive behavior. Peripheral or physical changes involve redirection of energy. Under these circumstances, oxygen and nutrients are redirected to allow for the stress response, both centrally and peripherally. An altered cardiovascular tone (increased blood pressure and heart rate) and simultaneous increase in respiratory rate, gluconeogenesis, and lipolysis together mobilize energy stores to vital organs. Nonvital processes, growth, reproduction, digestion, and immune function, are at the same time inhibited, aiming in supporting survival [6].

The adaptive response is coordinated by the central and peripheral limbs of the stress system. The system constitutes of the parvicellular corticotropin-releasing hormone $(\mathrm{CRH})$ and arginine-vasopressin neurons of the paraventricular nuclei of the hypothalamus, the $\mathrm{CRH}$ neurons of the paragigantocellular and parabrachial nuclei of the medulla, and the locus coeruleus and the catecholaminergic neurons of the locus coeruleus and other cell groups in the medulla and pons. The peripheral limb of the stress system contains the HPA axis, the efferent sympathetic-adrenomedullary system, and the components of the parasympathetic system [10].

Hypothalamic CRH is the principal regulator of the HPA axis and therefore has a coordinating role in stress response. $\mathrm{CRH}$ is responsible for secretion of adrenocorticotropin hormone (ACTH) from the pituitary gland. $\mathrm{CRH}$ has a synergistic interaction with arginine-vasopressin, catecholamines, angiotensin II, and oxytocin [6]. ACTH subsequently acts on the adrenal cortex to promote the secretion of glucocorticoids and adrenal androgens by the zona fasciculata and reticularis and participates in the control of aldosterone secretion by the zona glomerulosa. Additional hormones, cytokines, and the autonomic nervous system (ANS) act on the adrenal cortex and regulate cortisol secretion [7]. 
Glucocorticoids have a main role in the control of stress response, by the regulation of the HPA axis and the negative feedback on the hypothalamus and pituitary, affecting the secretion of $\mathrm{CRH}$ and ACTH, respectively. This normal feedback mechanism limits an individual's exposure to endogenous glucocorticoids, thus minimizing the catabolic, antireproductive, and immunosuppressive effects [11].

Central feedback at the level of the hypothalamus through reciprocal connections, with noradrenergic neurons, also regulates $\mathrm{CRH}$ production. Serotonin and acetylcholine cause positive stimulation to $\mathrm{CRH}$ and noradrenergic neurons, in contrast with glucocorticoids, $\gamma$-aminobutyrate, ACTH, and opioid peptides which inhibit $\mathrm{CRH}$ and noradrenergic neurons $[6,7,10]$.

The ANS responds rapidly to stressors and controls a wide range of functions. Cardiovascular, respiratory, gastrointestinal, renal, endocrine, and other systems are regulated by the sympathetic nervous system and the parasympathetic nervous system. The parasympathetic system and sympathetic systems have opposing functions and act to antagonize the effect of the other [11].

The sympathetic system has a humoral contribution, providing most of the circulating epinephrine and some of the norepinephrine from the adrenal medulla. In addition to the classic neurotransmitters acetylcholine and norepinephrine, both sympathetic and parasympathetic subdivisions of the ANS contain several subpopulations of target-selective and neurochemically coded neurons that express a variety of neuropeptides and in some cases ATP, nitric oxide, lipid mediators of inflammation, $\mathrm{CRH}$, neuropeptide $Y$, somatostatin (SS), enkephalin, neurotensin, and substance P [11].

Moreover, the stress system stimulates 3 other major CNS elements: the mesocorticolimbic dopaminergic or "reward" system [12], the amygdala-hippocampus complex [13], and the hypothalamic arcuate nucleus proopiomelanocortin neuronal system ( $\alpha$-melanocyte-stimulating hormone and $\beta$-endorphin). In addition, there are interactions with thermoregulatory and appetite-satiety centers of the CNS [14].

\section{Factors of Optimal Growth during Childhood and Adolescence}

Growth is a complex dynamic process, with changing multifactorial influences through fetal life, infancy, childhood, and puberty. Growth at each of these developmental stages is determined by the interplay of factors including genetics, environmental, socioeconomic, developmental, behavioral, nutritional, metabolic, biochemical, and hormonal factors [15]. It is divided into 3 stages, according to the infancy-childhood-puberty growth model [2].

\section{Growth during Infancy}

Growth rate is high $(25 \mathrm{~cm} /$ year $)$ during the first year of life slowing in the second year. Nutrition is the main factor influencing growth during the first 2 years of life, and any nutritional difficulties or changes may impact height velocity and consequently height [15].

\section{Growth during Childhood}

After the 2 first years of life, children generally have a steadier growth until the onset of puberty. In this stage, hormonal regulators growth hormone $(\mathrm{GH})$-insulin-like growth factor 1 (IGF-1) and thyroid hormones are more important for growth than during the first years of life [15]. $\mathrm{GH}$ is the main hormone, which stimulates hepatic IGF-1 production and chondrogenesis in the growth plate [3]. $\mathrm{GH}$ secretion is controlled by 3 peptide hormones, hypothalamic GH-releasing hormone, hypothalamic SS, and ghrelin. IGF-1 mediates a negative feedback control of $\mathrm{GH}$ secretion by acting directly on the somatotroph and on hypothalamic GH-releasing hormone and SS neurons. Moreover, GH secretion is also regulated by metabolic cues (insulin, glucose, and nonesterified fatty acids inhibit secretion while certain amino acids, such as arginine, stimulate secretion) and adiposity (negative effect) [16]. Thyroid hormones have an important role on growth. Throughout growth, thyroid hormones regulate bone turnover and bone mineral density, stimulate clonal expansion of chondrocyte progenitor cells, inhibit subsequent cell proliferation, and promote hypertrophic chondrocyte differentiation and cell volume expansion [17].

\section{Growth during Puberty}

Puberty is the transitional period between childhood and adulthood when substantial growth, development of secondary sex characteristics, and reproductive capacity are attained. The onset of puberty is triggered by the combined action of the somatotropic (GH/IGF-1) and gonadotropic (gonadotropin-releasing hormone [ $\mathrm{GnRH}]$ - luteinizing hormone/follicle-stimulating hormone - sex steroid) hormone axes, the latter of which stimulates the former to produce the pubertal growth spurt [18]. The maximum growth rate, peak height velocity, occurs during puberty at around 12 years in girls and 14 years in boys. However, there is a large individual as well as ethnic variation in the timing and tempo of pubertal development and growth patterns [16]. 


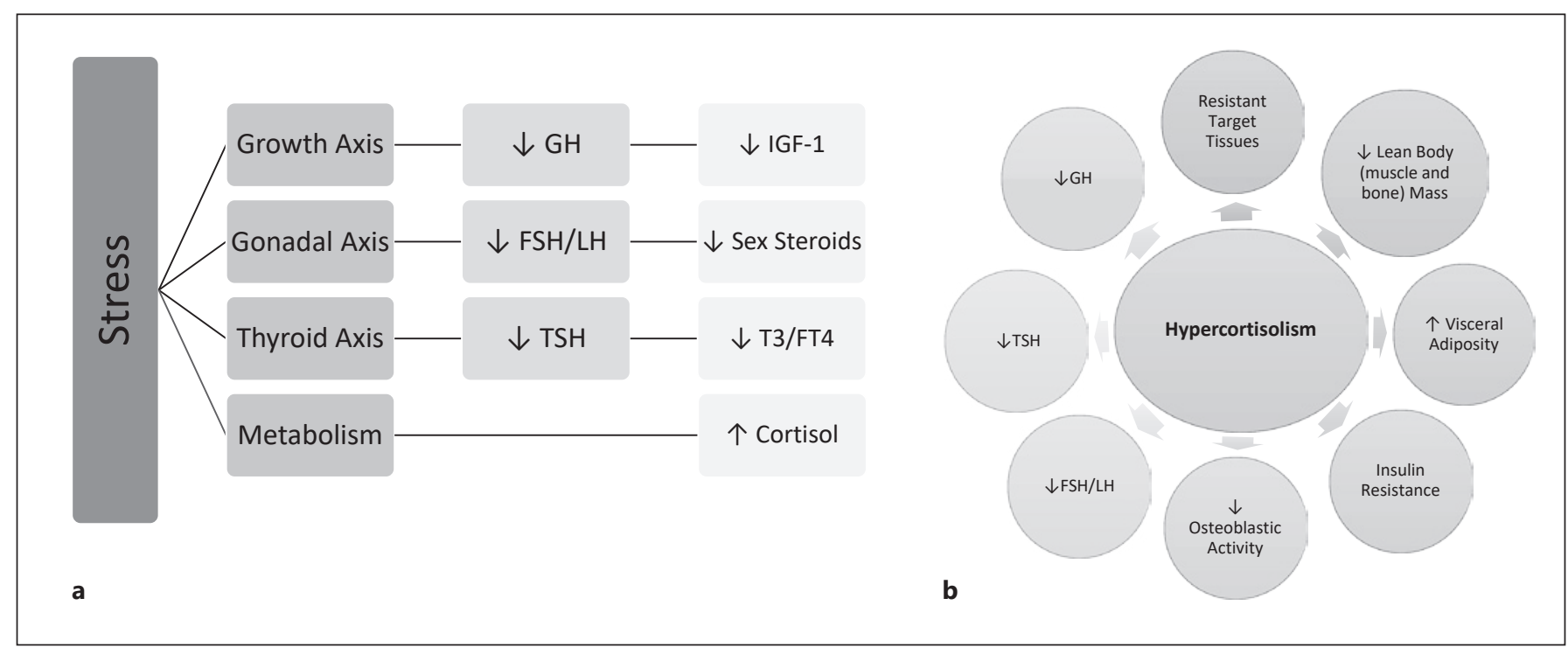

Fig. 1. The detrimental effect of stress on growth and metabolism. a Chronic activation of stress inhibits the growth axis, gonadal axis, and thyroid axis and increases the production of cortisol. b Hypercortisolism consequences on growth. FSH, follicle-stimulating hormone; LH, luteinizing hormone; TSH, thyroid-stimulating hormone.

\section{Leptin}

Leptin is a hormone secreted mainly by white adipose cells but is also produced in other tissues such as skeletal muscle, placenta, and pituitary gland. Leptin stimulates $\mathrm{GH}$ secretion by acting at the level of the hypothalamus [19]. It has also been shown to have a local effect in the growth plate by stimulating chondrocyte proliferation and cell differentiation [20].

\section{Growth-Related Hormonal Adaptive Response of Stress}

The adaptive response of stress occurs in 2 phases. The first phase begins within seconds and involves: (i) increased release of epinephrine and norepinephrine from the sympathetic nervous system; (ii) secretion of hypothalamic CRH into the hypophyseal portal system and subsequent enhanced release of ACTH; (iii) decreased release of hypothalamic GnRH followed by decreased secretion of follicle-stimulating hormone and luteinizing hormone from the anterior pituitary; (iv) enhanced secretion of pituitary-derived prolactin and $\mathrm{GH}$ and increased release of glycogen from the pancreas. The second phase of hormonal secretion occurs later in which glucocorticoid secretion dominates [21].
In most circumstances of health, the stress response is designed to be an acute time-limited response in which the initial stressor is present for a short duration only. The usually time-limited stress response is at once antigrowth, antireproductive, catabolic, and immunosuppressive. In short term, these effects are beneficial and have no lasting adverse consequences to the individual. However, chronic activation of the stress system may lead to a maladaptive stress response in part related to a sustained increase in $\mathrm{CRH}$ and glucocorticoid production [7]. Under these circumstances of chronic activation of stress, the response of the HPA axis becomes maladaptive with consequential negative impacts on growth, thyroid function, reproduction-puberty, and metabolism (shown in Fig. 1).

\section{Impact on $\mathrm{GH} / \mathrm{IGF}-1$ Axis}

The GH/IGF-1 axis is inhibited at many levels during stress. First, the prolonged activation of the HPA axis culminates in increased levels of circulating glucocorticoids which have a direct effect on suppression of GH secretion from the pituitary gland. Glucocorticoids also inhibit the effects of IGF-1 and GH on their target tissues [22]. Conversely, acute elevations of GH concentration in plasma may occur at the onset of the stress response or after acute administration of glucocorticoids, presumably through stimulation of the $\mathrm{GH}$ gene by glucocorticoids through glucocorticoid-responsive elements in its promoter region. 
This stimulation of GH is not sustained with chronic activation of stress [23]. In addition, $\mathrm{CRH}$, which is elevated during stress, stimulates hypothalamic SS secretion and causes GH suppression.

\section{Impact on Thyroid Function}

Activation of the HPA axis is associated with decreased production of TSH and inhibition of the conversion of the relatively inactive thyroxin to the more biologically active triiodothyronine in peripheral tissues (the "sick euthyroid" syndrome) [24]. The effect, in acute stress, may serve to conserve energy and therefore be adaptive in short term. The exact mechanism is not known, but both increased levels of SS and glucocorticoids have been proposed. In addition, inflammatory stress may have a putative role in inhibition of TSH secretion through the effect of pro-inflammatory cytokines on both the hypothalamus and the pituitary [11].

\section{Impact on Hypothalamic-Pituitary-Gonadal Axis}

Pubertal growth is affected not only through inhibition of GH but also through the inhibition of gonadotrophins. The suppression of GnRH neurons occurs by direct action of CRH on GnRH neurons of the arcuate nucleus of the hypothalamus and indirectly through arcuate proopiomelanocortin neuron b-endorphin [25]. Glucocorticoids inhibit $\mathrm{GnRH}$, gonadotrophins, and the gonads and render target tissues of sex steroids resistant to these hormones. Suppression of gonadal function, in chronic HPA axis activation, has been demonstrated in highly trained athletes of both sexes [26], in ballet dancers [11], and in individuals diagnosed with anorexia nervosa [27] or during episodes of negative energy balance [28]. During inflammatory stress, cytokines have also been proposed to suppress the reproductive system [11].

\section{Impact on Metabolism}

Glucocorticoids directly inhibit GH, gonadotropins, and TSH secretion and make the target tissues of sex steroids and growth factors resistant to these hormones. Thus, glucocorticoids antagonize the beneficial actions of $\mathrm{GH}$ and sex steroids on fat tissue (lipolysis) and muscle and bone anabolism. Chronic activation of the stress system would be expected to increase visceral adiposity, decrease lean body (muscle and bone) mass, and suppress osteoblastic activity [29]. A clinical phenotype, relating to cortisol excess, is shared amongst individuals with Cushing syndrome and with a "pseudo-Cushing syndrome" caused by combined diagnoses of melancholic depression or chronic anxiety disorder and the metabolic syndrome (visceral adiposity, insulin resistance, dyslipidemia, and hypertension) [7].

Stress and Growth
Stress may have additional adverse effects including osteoporosis and insulin resistance. Hypercortisolism, decreased GH/IGF-1 concentrations, and hypogonadism together may be responsible for a low bone turnover osteoporosis [7]. The stress response combined with cortisol excess induces a state of relative insulin resistance through both hepatic gluconeogenesis and peripheral resistance to insulin [30].

\section{Adversities and the Consequences}

Infancy, childhood, and adolescence are periods of increased plasticity for the stress system and are, therefore, particularly sensitive to stressors. Excessive or sustained activation of the stress system during these critical periods may have more dramatic effects. Stressors may have a permanent effect on the organism, reminiscent of the "organizational" effects of several hormones exerted on certain target tissues, which lasts long after cessation of the exposure to these hormones $[7,31]$.

Exposure to frequent, prolonged, or intensely negative experiences in childhood (early-life adversity) has been associated with long-term negative health outcomes, including ischemic heart disease, cancer, diabetes, asthma, and premature death, among others [32]. Early childhood, adolescent, and concurrent stress predicted adult health outcomes at the age of 32 years [33]. Early childhood and adolescent stress both showed a "dual-risk" pattern, such that experiencing higher stress, and predicted the worst health outcomes. Higher maternal sensitivity, however, buffered these deleterious effects [33].

\section{Models of Chronic Stress Affecting Growth}

\section{Prenatal Stress}

Prenatal adversities including prenatal maternal psychosocial stress [34], alcohol use [35], and factors increasing the risk for low birth weight [36] have consistently been associated with HPA hyperreactivity to stress, a process known as "prenatal programming." Mothers contribute behavioral, chemical, and nutritional input during the fetal and early postnatal period and thus define the earlylife environment. In addition, microbiome and microbial composition, which has been associated with growth in infants and children, is affected by prenatal stress [37].

Early adversities have been shown to have epigenetic effects on gene expression [38], which can explain how the early environment affects the adult phenotype. Since genetic 
influences operate throughout life [39], studies disentangling genetic and fetal environmental factors on stress responses and health should investigate their interplay across development.

\section{Malnutrition}

The first 2 years of life is a critical period when adequate nutrition and appropriate care are essential. Malnutrition is associated with a double burden: stunting of linear growth and subsequent obesity and noncommunicable diseases in adults [40]. Malnutrition and chronic illness affect growth rate, and, with increasing severity and duration, it may result in a shorter than predicted adult height. Nevertheless, catch-up in height can occur even with longstanding starvation, as noted in Norwegian children following the German occupation during World War II [41]. The catch-up growth is characterized by the height velocity above the upper limit of normal for age and sex at least 1 year following a transient period of growth retardation [18].

Infantile malnutrition is characterized by hypercortisolism, diminished responses to $\mathrm{CRH}$ stimulation, incomplete suppression of the HPA axis by dexamethasone, and alterations in the thyroid function reminiscent of the sick euthyroid syndrome [7]. All these abnormalities are restored following nutritional rehabilitation [42]. This condition is characterized by an increase in GH secretion, which is due to starvation-induced hyposecretion of IGF-1 [7].

\section{Psychosocial Short Stature}

Psychosocial short stature is characterized by growth failure associated with an abusive environment. The characteristic clinical presentation is either of short stature or growth failure with a normal body mass index and greater than anticipated appetite. Psychosocial short stature has the characteristic features of partial and temporary reversible GH deficiency, with a dramatic improvement in growth rate upon a change to a more suitable environment [43]. In addition to low GH secretion, children have impaired thyroid function and biochemical findings reminiscent of those of the sick euthyroid syndrome [7].

\section{Reactive Attachment Disorder of Infancy}

Reactive attachment disorder of infancy is a similar condition to psychosocial short stature. The disorder develops when attachment between an infant and their primary caregiver does not happen, or it is interrupted due to negligent care. This often occurs when the caregiver is intellectually disabled, when they lack parenting skills, or when there is a frequent change in caregivers. The condition usually presents before the age of 8 months with failure to thrive, lack of developmentally appropriate social responsiveness, and apathy [44].

Maternal separation is a stressful situation for an infant. The specific suppression of GH is one of the hallmarks of this condition. As described above, the chronic activation of the stress system leads to a sustained increase in CRH and glucocorticoid production which cause hypothalamic SS secretion, suppression of GH secretion from the pituitary gland, and resistance of target tissues to IGF-1 and $\mathrm{GH}$ actions. These children recover without any medications during hospitalization or after placement into a caring environment [45]. It is sometimes observed in premature infants, especially after prolonged hospitalization in the intensive care unit [7].

\section{Hospitalization/Emotional Deprivation}

Hospitalization, if prolonged, can cause growth and developmental retardation of children. This is an example of nonorganic failure to thrive particular to children resident in institutions for extended periods resulting in emotional deprivation. Observations in a foundling hospital suggested that very few of the children were of normal height or weight, and that the mortality rate was much higher than average, in spite of cleanliness and adequate food [18]. In contrast, observations in a prison hospital where mothers fed and interacted with their infants and where toys, perceptual stimuli, and opportunities for movement were available, the infants thrived, and the mortality rate was considerably lower [18].

Children who experienced institutional care during infancy have impaired responsiveness of the HPA axis to psychosocial stressors. The emotional and/or nutritional deprivation precludes adequate environmental stimulation and nutrition for normal physiologic growth, and the stress of psychological harassment underlies abnormal circadian rhythms and suppression of GH release [46]. The blunted cortisol response can carry over into adulthood even if the children are placed in supportive, well-resourced homes [47]. However, the peripubertal period may be a second period of plasticity to permit the HPA axis to recalibrate to a physiological state [18].

\section{Inhibited Child Syndrome}

Inhibited child syndrome involves a hyperactive or hyperreactive amygdala generating excessive and prolonged fear and hence anxiety. The predicted somatic consequences of this hyperactive stress system include delayed growth and puberty and components of the metabolic syndrome, such as visceral obesity, insulin resistance, hypertension, dyslipidemia, cardiovascular disease, and osteoporosis [7].
Mousikou/Kyriakou/Skordis 


\section{Wars/Immigration}

In the stressors inflicted upon by war in childhood, wasting and severe acute malnutrition are common indicators to assess the impact in the acute phase, whereas poor growth may reflect longer-term effects. Poor growth has been more frequently documented in conflict-affected countries than the subregional trends and does not show improvement after conflict [48]. Possible negative effects on growth, health, and psychosocial adaptation have been reported amongst immigrant children living in low-income, disadvantaged communities with a high prevalence of poor lifestyle habits. In general, age at menarche was lower in immigrant girls, while male pubertal progression seemed faster in immigrants than in European natives, even when puberty began later [49].

\section{Disease}

Chronic illness (congenital heart disease, chronic kidney disease, liver disease, cystic fibrosis, and cancer) puts children at risk for developing malnutrition. The pathogenetic mechanisms causing malnutrition in children with chronic disease are multifactorial and are often related to the underlying disease and possible inflammation or malabsorption, and also nonillness-associated factors [50].

Growth can be negatively impacted in context of chronic disease by a combination of any of malnutrition, inflammation, and treatments. There is also a possible role of chronic activation of the stress response which often accompanies living with a chronic illness which can also inhibit growth. The persistent activation of the HPA axis in the chronic stress response and in depression probably impairs the immune response and contributes to the development and progression of some types of cancer [51].

\section{Intense Exercise}

Intense physical training even in healthy children (i) alters stress, immune, and inflammatory mediators including peripheral blood mononuclear cells and circulating pro- and anti-inflammatory cytokines, which play important roles in a variety of pediatric and adult diseases; (ii) stimulates the production of reactive oxygen species which play a key role in the development of metabolic syndrome, type 2 diabetes, hypertension, and cardiovascular disease; and (iii) has long-term health effects in critical periods (early life and in the pubertal transition) [52].

Rhythmic gymnasts performing under conditions of high intensity are exposed to high levels of psychological stress and intense physical training. These factors likely contribute to the observed pattern of growth and delay in skeletal maturation and pubertal development. Despite the delay in skeletal maturation, genetic predisposition of height is not only preserved but also sometimes exceeded [53].

\section{Conclusion}

Physical and emotional stress is commonly encountered throughout the lifespan. The periods of infancy, childhood, and adolescence which are important for growth and development also represent times of increased vulnerability to stressors. Early-life adversities may have a greater influence on growth and puberty. The activation of the stress system produces behavioral, physiological, and biochemical changes as part of an adaptive response. The aims of this response are both in improving survival and conserving energy and include suppression of the GH/IGF-1, hypothalamic-pituitarygonadal, and hypothalamic-pituitary-thyroid axes such that stress is at the same time antigrowth, antireproductive, and catabolic. In the longer term, hypercortisolism can be responsible for an increase in visceral adiposity, decreased lean body (muscle and bone) mass, suppression of osteoblastic activity resulting in osteoporosis, and an increase in insulin resistance.

Chronic stress is associated with negative physical and mental health outcomes later in life. Children and adolescents may be especially vulnerable to severe stressors with potentially irreversible effects if these exposures occur during critical periods of development and brain maturation. Interventions to manage and decrease stress during childhood and adolescence in children should aim to achieve optimal growth and timing of puberty.

\section{Conflict of Interest Statement}

The authors have no financial disclosures or conflicts of interest relevant to this article to disclose.

\section{Funding Sources}

This article did not receive any specific grant from funding agencies in the public, commercial, or not-for-profit sectors.

\section{Author Contributions}

The first draft of the manuscript was written by M. Mousikou. N. Skordis provided overall supervision. All authors extensively reviewed the manuscript. All authors read and approved the final manuscript. 


\section{References}

1 Hermanussen M, Bogin B. Auxology - an editorial. Ital J Pediatr. 2014 Jan 23;40:8.

2 Karlberg J. A biologically-oriented mathematical model (ICP) for human growth. Acta Paediatr Scand Suppl. 1989;350:70-94.

3 Benyi E, Sävendahl L. The physiology of childhood growth: hormonal regulation. Horm Res Paediatr. 2017;88(1):6-14.

4 Eveleth PB, Tanner JM. Worldwide variation in human growth. $2^{\text {a }}$ nd ed. Cambridge University Press; 1990. p. 397. figuras, tabelas, bibliografia. (Brochura) ISBN 0-521-35916-3

5 Delemarre-van de Waal HA. Environmental factors influencing growth and pubertal development. Environ Health Perspect. 1993 Jul; 101(Suppl 2):39-44.

6 Chrousos GP, Gold PW. The concepts of stress and stress system disorders. Overview of physical and behavioral homeostasis. JAMA. 1992 Mar 4;267(9):1244-52.

7 Charmandari E, Kino T, Souvatzoglou E, Chrousos GP. Pediatric stress: hormonal mediators and human development. Horm Res. 2003;59(4):161-79.

8 Johnson EO, Kamilaris TC, Chrousos GP, Gold PW. Mechanisms of stress: a dynamic overview of hormonal and behavioral homeostasis. Neurosci Biobehav Rev. 1992;16(2): 115-30.

9 de Wied D. Pituitary adrenal system hormones and behaviour. Acta Endocrinol Suppl. 1977; 214:9-18.

10 Stratakis CA, Gold PW, Chrousos GP. Neuroendocrinology of stress: implications for growth and development. Horm Res. 1995;43(4):162-

11 Tsigos C, Chrousos GP. Hypothalamic-pituitary-adrenal axis, neuroendocrine factors and stress. J Psychosom Res. 2002 Oct;53(4): 865-71.

12 Diorio D, Viau V, Meaney MJ. The role of the medial prefrontal cortex (cingulate gyrus) in the regulation of hypothalamic-pituitaryadrenal responses to stress. J Neurosci. 1993 Sep;13(9):3839-47.

13 McEwen BS. Physiology and neurobiology of stress and adaptation: central role of the brain. Physiol Rev. 2007 Jul;87(3):873-904.

14 Mora F, Lee TF, Myers RD. Involvement of alpha- and beta-adrenoreceptors in the central action of norepinephrine on temperature, metabolism, heart and respiratory rates of the conscious primate. Brain Res Bull. 1983 Nov; 11(5):613-6.

15 Veldhuis JD, Roemmich JN, Richmond EJ, Rogol AD, Lovejoy JC, Sheffield-Moore M, et al. Endocrine control of body composition in infancy, childhood, and puberty. Endocr Rev. 2005 Feb;26(1):114-46.

16 Meinhardt UJ, Ho KK. Modulation of growth hormone action by sex steroids. Clin Endocrinol. 2006 Oct;65(4):413-22.

17 Bassett JH, Williams GR. Role of thyroid hormones in skeletal development and bone maintenance. Endocr Rev. 2016 Apr;37(2):135-87.
18 Rogol AD. Emotional deprivation in children: growth faltering and reversiblehypopituitarism. Front Endocrinol. 2020 Oct 7;11:596144.

19 Odle AK, Haney A, Allensworth-James M, Akhter N, Childs GV. Adipocyte versus pituitary leptin in the regulation of pituitary hormones: somatotropes develop normally in the absence of circulating leptin. Endocrinology. 2014 Nov;155(11):4316-28.

20 Nakajima R, Inada $H$, Koike T, Yamano T. Effects of leptin to cultured growth plate chondrocytes. Horm Res. 2003;60(2):91-8.

21 Sapolsky RM, Romero LM, Munck AU. How do glucocorticoids influence stress responses? Integrating permissive, suppressive, stimulatory, and preparative actions. Endocr Rev. 2000 Feb; 21(1):55-89.

22 Burguera B, Muruais C, Peñalva A, Dieguez C, Casanueva FF. Dual and selective actions of glucocorticoids upon basal and stimulated growth hormone release in man. Neuroendocrinology. 1990 Jan;51(1):51-8.

23 Casanueva FF, Burguera B, Muruais C, Dieguez C. Acute administration of corticoids: a new and peculiar stimulus of growth hormone secretion in man. J Clin Endocrinol Metab. 1990 Jan;70(1):234-7.

24 Benker G, Raida M, Olbricht T, Wagner R, Reinhardt W, Reinwein D. TSH secretion in Cushing's syndrome: relation to glucocorticoid excess, diabetes, goitre, and the "sick euthyroid syndrome”. Clin Endocrinol. 1990 Dec;33(6): 777-86.

25 Rivier C, Rivier J, Vale W. Stress-induced inhibition of reproductive functions: role of endogenous corticotropin-releasing factor. Science. 1986 Feb 7;231(4738):607-9.

26 Cano Sokoloff N, Misra M, Ackerman KE. Exercise, training, and the hypothalamicpituitary-gonadal axis in men and women. Front Horm Res. 2016;47:27-43.

27 Schorr M, Miller KK. The endocrine manifestations of anorexia nervosa: mechanisms and management. Nat Rev Endocrinol. 2017 Mar; 13(3):174-86

28 Rivier C, Rivest S. Effect of stress on the activity of the hypothalamic-pituitary-gonadal axis: peripheral and central mechanisms. Biol Reprod. 1991 Oct;45(4):523-32.

29 Chrousos GP. The role of stress and the hypothalamic-pituitary-adrenal axis in the pathogenesis of the metabolic syndrome: neuroendocrine and target tissue-related causes. Int J Obes Relat Metab Disord. 2000 Jun;24 Suppl 2:S50-5.

30 Bamberger CM, Schulte HM, Chrousos GP. Molecular determinants of glucocorticoid receptor function and tissue sensitivity to glucocorticoids. Endocr Rev. 1996 Jun;17(3):245-61.

31 Chrousos GP. Organization and integration of the endocrine system. Sleep Med Clin. 2007 Jun;2(2):125-45.

32 Bucci M, Marques SS, Oh D, Harris NB. Toxic stress in children and adolescents. Adv Pediatr. 2016 Aug;63(1):403-28.
33 Farrell AK, Simpson JA, Carlson EA, Englund MM, Sung S. The impact of stress at different life stages on physical health and the buffering effects of maternal sensitivity. Health Psychol. 2017 Jan;36(1):35-44.

34 Entringer S, Kumsta R, Hellhammer DH, Wadhwa PD, Wüst S. Prenatal exposure to maternal psychosocial stress and HPA axis regulation in young adults. Horm Behav. 2009 Feb;55(2):292-8.

35 Hellemans KG, Sliwowska JH, Verma P, Weinberg J. Prenatal alcohol exposure: fetal programming and later life vulnerability to stress, depression and anxiety disorders. Neurosci Biobehav Rev. 2010 May;34(6):791-807.

36 Wüst S, Entringer S, Federenko IS, Schlotz W, Hellhammer DH. Birth weight is associated with salivary cortisol responses to psychosocial stress in adult life. Psychoneuroendocrinology. 2005 Jul;30(6):591-8.

37 Lu A, Petrullo L, Carrera S, Feder J, SchneiderCrease I, Snyder-Mackler N. Developmental responses to early-life adversity: evolutionary and mechanistic perspectives. Evol Anthropol. 2019 Sep;28(5):249-66.

38 Oberlander TF, Weinberg J, Papsdorf M, Grunau R, Misri S, Devlin AM. Prenatal exposure to maternal depression, neonatal methylation of human glucocorticoid receptor gene (NR3C1) and infant cortisol stress responses. Epigenetics. 2008 Mar-Apr;3(2):97-106.

39 Schlotz W, Phillips DI. Fetal origins of mental health: evidence and mechanisms. Brain Behav Immun. 2009 Oct;23(7):905-16

40 Black RE, Victora CG, Walker SP, Bhutta ZA, Christian P, de Onis M, et al. Maternal and child undernutrition and overweight in lowincome and middle-income countries. Lancet. 2013 Aug 3;382(9890):427-51.

41 Brundtland GH, Liestøl K, Walløe L. Height, weight and menarcheal age of Oslo schoolchildren during the last 60 years. Ann Hum Biol. 1980 Jul-Aug;7(4):307-22.

42 Malozowski S, Muzzo S, Burrows R, Leiva L, Loriaux L, Chrousos G, et al. The hypothalamicpituitary-adrenal axis in infantile malnutrition. Clin Endocrinol. 1990 Apr;32(4):461-5.

43 Stanhope R, Gohlke B. The aetiology of growth failure in psychosocial short stature. J Pediatr Endocrinol Metab. 2003 Mar;16(3):365-6.

44 Richters MM, Volkmar FR. Reactive attachment disorder of infancy or early childhood. J Am Acad Child Adolesc Psychiatry. 1994 Mar-Apr;33(3):328-32.

45 Katz LM, Nathan L, Kuhn CM, Schanberg SM. Inhibition of $\mathrm{GH}$ in maternal separation may be mediated through altered serotonergic activity at 5-HT2A and 5-HT2C receptors. Psychoneuroendocrinology. 1996 Feb;21(2):219-35.

46 Miller BS, Spratt EG, Himes JH, Condon D, Summer A, Papa CE, et al. Growth failure associated with early neglect: pilot comparison of neglected US children and international adoptees. J Pediatr Endocrinol Metab. 2015 Jan;28(1-2):111-5. 
47 Hostinar CE, Johnson AE, Gunnar MR. Early social deprivation and the social buffering of cortisol stress responses in late childhood: an experimental study. Dev Psychol. 2015 Nov; 51(11):1597-608.

48 Boerma T, Tappis H, Saad-Haddad G, Das J, Melesse DY, DeJong J, et al. Armed conflicts and national trends in reproductive, maternal, newborn and child health in sub-Saharan Africa: what can national health surveys tell us? BMJ Glob Health. 2019 Jun 24;4(Suppl 4):e001300.
49 Gualdi-Russo E, Toselli S, Masotti S, Marzouk D, Sundquist K, Sundquist J. Health, growth and psychosocial adaptation of immigrant children. Eur J Public Health. 2014 Aug; 24(Suppl 1):16-25.

50 Larson-Nath C, Goday P. Malnutrition in children with chronic disease. Nutr Clin Pract. 2019 Jun;34(3):349-58.

51 Reiche EM, Nunes SO, Morimoto HK. Stress, depression, the immune system, and cancer. Lancet Oncol. 2004 Oct;5(10):617-25.
52 Cooper DM, Nemet D, Galassetti P. Exercise, stress, and inflammation in the growing child: from the bench to the playground. Curr Opin Pediatr. 2004 Jun;16(3):28692.

53 Georgopoulos NA, Markou KB, Theodoropoulou A, Vagenakis GA, Benardot D, Leglise $\mathrm{M}$, et al. Height velocity and skeletal maturation in elite female rhythmic gymnasts. J Clin Endocrinol Metab. 2001 Nov;86(11):515964. 